\title{
Studying Heavy Metals on Antarctica by Using Non Invasive Biotic Samples of Penguins
}

\author{
José E Celis ${ }^{1 *}$, Daniel González-Acuña ${ }^{1}$, Winfred Espejo ${ }^{2}$, Ricardo Barra ${ }^{2}$ and Gustavo Chiang ${ }^{3}$ \\ ${ }^{1}$ Department of Animal Science, University of Concepción, Chile \\ ${ }^{2}$ Department of Aquatic Systems, University of Concepción, Chile \\ ${ }^{3}$ Melimoyu Ecosystem Research Institute, Chile \\ *Corresponding author: José E Celis, Department of Animal Science, University of Concepción, P.0 Box 537, Chillán, Chile
}

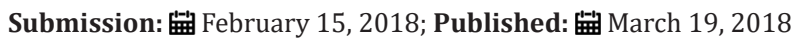

\begin{abstract}
Antarctica is one of the most surprising places in terms of biodiversity, and is one of the regions less affected by humans. The study of pollution in Antarctica can help us understand the real influence of human activities on the environmental pollution from polar regions. Trace elements are worrisome to biota for their effects on health and ecosystems. These chemicals enter the water through natural processes and human activities, and can affect wildlife and humans. The northern of Antarctic Peninsula and the South Shetland islands are particularly vulnerable because of their proximity to the continent and for having major human pressure. Our studies have focused on the determination of metals in penguin excreta, as they are non-invasive materials which can be suitable for the monitoring of chemicals in the environment.
\end{abstract}

\section{Introduction}

Heavy metals (or most recently known as trace elements) are chemicals whose exposition can produce acute and chronic toxicity, thus affecting the central nervous and endocrine systems, liver and kidneys of mammals and birds. Those effects can be more severe on wildlife from cold regions such as Antarctica, due to their immunological systems are less prepared to deal with xenobiotic compounds. Trace elements are divided as essentials (such as $\mathrm{Cu}, \mathrm{Zn}, \mathrm{Mn}, \mathrm{Fe}, \mathrm{Se}$ ) and non-essentials (such as $\mathrm{Al}, \mathrm{As}$, $\mathrm{Cd}, \mathrm{Hg}, \mathrm{Pb}$ ). Essential elements are required in small amounts to perform vital functions for the maintenance of biota, but they can be very toxic if their levels exceed the physiological requirements of the organism. Non-essential elements have no known function in the animal body, and their presence may be toxic [1]. In aquatic environments, trace elements contamination is a great concern due to the implications these chemicals may have on both wildlife and human health [2]. These elements enter the water through natural erosion, geochemical cycles, industrial processes and agricultural practices [3].

Birds tend to be more sensitive to environmental contaminants than other vertebrates [4], and aquatic birds are especially important for biomonitoring due to their wide distribution and their essential role in aquatic ecosystems, being especially susceptible to changes that occur by human influence in their habitats [5-7]. In Antarctica, the study of trace elements in penguins is valuable, because they are animals that exclusively inhabit the Southern Hemisphere and represent about $90 \%$ of the bird biomass of the Southern Ocean
[8]. The levels of metals and other contaminants in penguins are directly related to the levels present in their diet, which depends on the amount of contaminants in the trophic food chain [9]. Currently, using living organism tissues as environmental bio indicators can be limited because the International agreements (Antarctic Treaty and the Scientific Committee for Antarctic Research), ethical behavior and conservation purposes. For those reasons, the use of non-invasive/non-lethal methods for sampling is an alternative to the capture and sacrifice of live specimens. Penguins feed on the sea and deposit their excreta ashore. Sea animal excrement can be used as an effective tool to biomonitor the degree of contamination by trace elements in the environment.

Our studies have focused on the measurement of metals in excreta of Gentoo (Pygoscelis papua), Adélie (Pygoscelis adeliae) and Chinstrap (Pygoscelis antarctica) penguins, which inhabit the Antarctic Peninsula. We have also studied the role of these birds as transporting of pollutants from coastal to terrestrial systems, assessing the metal levels in the soil from the colonies of penguins and in un-impacted areas away from the colonies. Our data have shown that there are higher levels of trace elements in the north area of the Antarctic Peninsula and South Shetland Islands, as compared to more extreme locations such as Avian Island, which present less anthropogenic activity. Additionally, the concentrations of trace elements tend to be higher in all nesting sites of penguin colonies, indicating that these birds are bio-transporting heavy metals to terrestrial environments, which could affect some endemic biota and alter the delicate biogeochemical cycles in Antarctica. These 
results are showing that there is evidence of increased human pressure in the north of the Antarctic Peninsula, probably due to tourist activities and scientific facilities, as well as for the transport of pollutants from countries in the Southern Hemisphere, implying a greater concentration of pollutants in that area than in the rest of the Antarctic continent.

This proves that the excreta of penguins are good indicators of the concentration of trace elements in polar environments. There are still scarce studies on the presence of trace elements in the excreta of penguins, which are necessary to set the base of environmental problems and to be able to see possible future scenarios that could be unleashed in Antarctica as a consequence of an increased anthropogenic pressure. It is therefore crucial to be able to know the baseline levels of trace elements in relatively uncontaminated areas in order to obtain specific data to compare the progress of pollution along time, in order to design adequate environmental monitoring plans to protect wildlife in Antarctica.

\section{References}

1. Nordberg M, Nordberg GF (2016) Trace element research-historical and future aspects. J Trace Elem Med Bio 38: 46-52.

2. Lavoie R, Jardine T, Chumchal M, Kidd K, Campbell L (2013) Biomagnification of mercury in aquatic food webs: a worldwide metaanalysis. Environ Sci Technol 47(23): 13385-13394.
3. Burger J, Gochfeld M (2000a) Effects of lead on birds (Laridae): a review of laboratory and field studies. J Toxicol Environ Health B Crit Rev 3(2): 59-78.

4. Zhang W, Ma J (2011) Water birds as bioindicators of wetland heavy metal pollution. Procedia Environ Sci 10: 2769-2774.

5. Barbieri E, de Andrade PE, Filippini A, Souza dos SI, Borges CA (2010) Assessment of trace metal concentration in feathers of seabird (Larus dominicanus) sampled in the Florianópolis, SC, Brazilian coast. Environ Monit Assess 169(1-9): 631-638.

6. Barbosa A, De Mas E, Benzal J, Diaz J, Motas M, et al. (2013) Pollution and physiological variability in gentoo penguins at two rookeries with different levels of human visitation. Antarct Sci 25(2): 329-338.

7. Kehrig HA, Hauser-Davis RA, Seixas TG, Fillmann G (2015) Traceelements, methylmercury and metallothionein levels in Magellanic penguin (Spheniscus magellanicus) found stranded on the Southern Brazilian coast. Mar Pollut Bull 96(1-2): 450-455.

8. Williams TD (1990) Annual variation in breeding biology of gentoo penguin, Pygoscelis papua, at Bird Island, South Georgia. Journal of Zoology of London 222(2): 247-258.

9. Espejo W, Celis JE, González-Acuña D, Banegas A, Barra R, et al. (2017) A global overview of exposure levels and biological effects of trace elements in penguins. Reviews of Environmental Contamination and Toxicology 245: 1-64.
Creative Commons Attribution 4.0 International License

For possible submissions Click Here

\section{Submit Article}

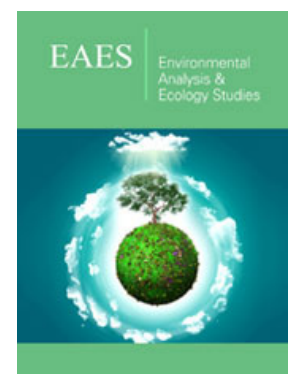

\section{Environmental Analysis \& Ecology Studies}

\section{Benefits of Publishing with us}

- High-level peer review and editorial services

- Freely accessible online immediately upon publication

- Authors retain the copyright to their work

- Licensing it under a Creative Commons license

- Visibility through different online platforms 